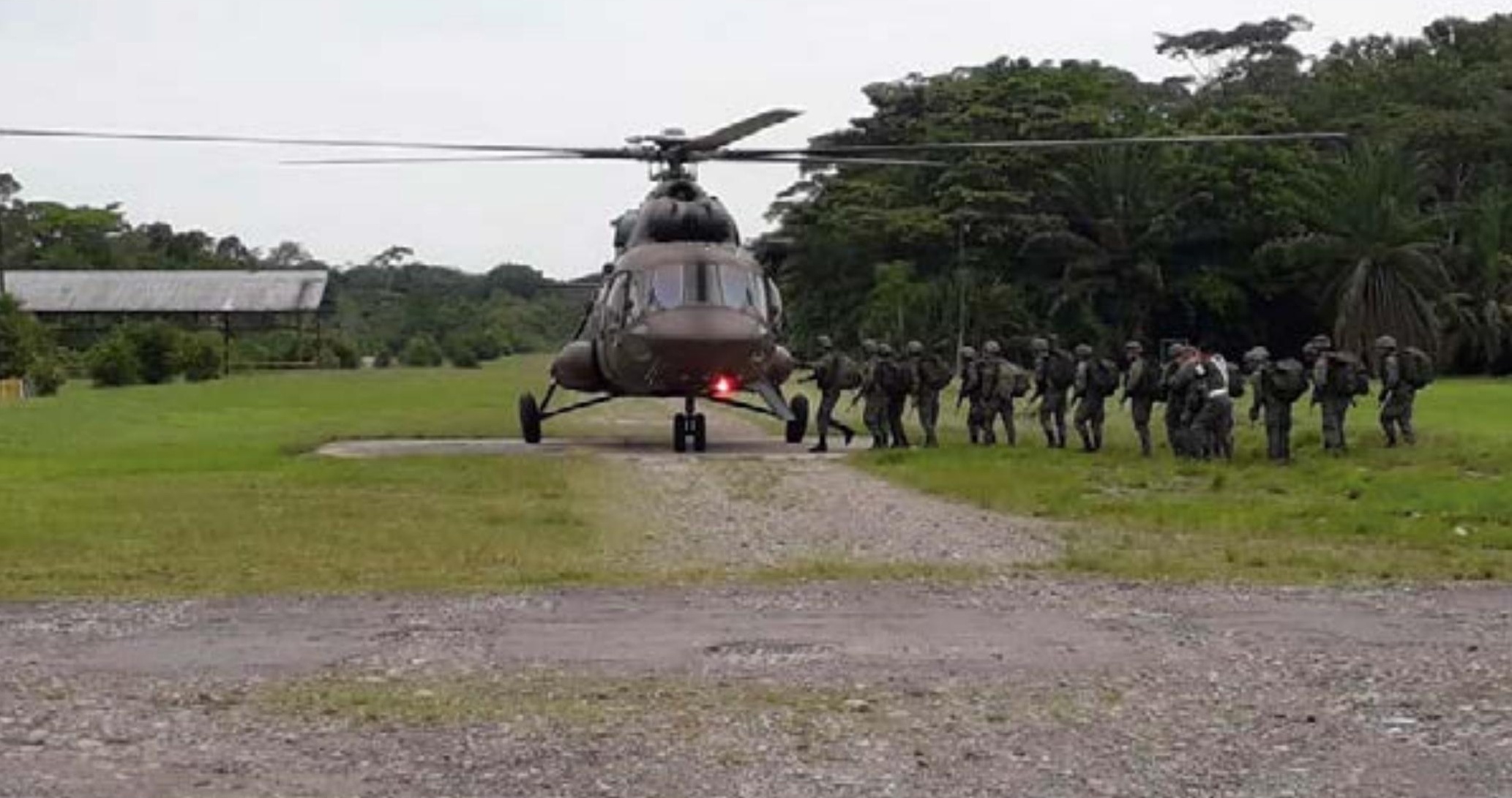

\title{
INFLUENCIA DEL CONFLICTO COLOMBIANO EN EL DESARROLLO DE LAS CAPACIDADES DE LAS FUERZAS ARMADAS ECUATORIANAS
}

Tcrn E.M Robert Gaona Abad

\section{RESUMEN}

El presente artículo tiene como objetivo, determinar a través de una metáfora simbiótica como la dinámica del conflicto colombiano ha afectado en nuestro país, bajo una óptica integral, resaltando el ámbito psicosocial y sobre todo el militar. Para ello es imprescindible conceptualizar las causas del conflicto, sus mutaciones, las relaciones de poder y sobre todo el escenario de influencia regional y mundial. Para finalmente poder visualizar el contexto que nos permita mirar prospectivamente a que nos enfrentaremos, y como podríamos mejorar nuestras capacidades militares diferenciadas, multipropósito, multifuncionales y modulares, para lograr una organización, equipamiento y entrenamiento eficiente, alcanzando una fuerza militar flexible, capaz de cumplir con la misión constitucional y poder enfrentar los conflictos híbridos, dentro del contexto de las operaciones multidominio, los ambientes operacionales emergentes, los avances tecnológicos y las probables capacidades de adversarios, amenazas y enemigos.

Palabras clave: Conflicto, poder, capacidades, conflictos híbridos, multidimensional, operaciones multidominio, incertidumbre, complejidad.

\section{ABSTRACT}

The objective of this article is to determine, through a symbiotic metaphor, how the dynamics of the Colombian conflict have affected in our country, from an integral perspective, highlighting the psychosocial and especially the military sphere. For this, it is essential to conceptualize the causes of the conflict, its mutations, power relations and, above all, the scenario of regional and world influence. To finally be able to visualize the context that allows us to look prospectively at what we will face, and how we could improve our differentiated, multipurpose, multifunctional and modular military capabilities, to achieve an efficient organization, equipment and training, 
reaching a flexible military force, able to fulfill with the constitutional mission and to be able to face hybrid conflicts, within the context of multi-domain operations, emerging operational environments, technological advances and the probable capabilities of adversaries, threats and enemies.

Keywords: Conflict, power, capabilities, hybrid conflicts, multidimensional, multidomain operations, uncertainty, complexity.

\section{Desarrollo}

Desde la década de los sesenta Colombia se halla inmersa en un conflicto armado que involucra múltiples actores: las guerrillas de izquierda, los paramilitares de derecha, los narcotraficantes, la delincuencia transnacional organizada, el gobierno, las fuerzas armadas, la sociedad civil, las autodefensas, los grupos disidentes y finalmente los carteles de la droga. Por lo tanto, resulta evidente que en los conflictos armados se conjuguen complejas variables, sin embargo, en el caso colombiano se atribuye la violencia política a múltiples factores, relacionados con, la capacidad gubernamental para advertir la violencia, convirtiéndose en el factor fundamental, así como también, a la falta de intervención política, de gobernabilidad, a la mala administración de los recursos económicos y principalmente a la ausencia del estado en algunas partes del territorio nacional, lo que facilitó la aparición y desarrollo del conflicto armado (Yaffe, 2011).

En este contexto, las transformaciones sociales, políticas y económicas del conflicto armado colombiano, han influido en sus características propias, como de una guerra irregular y de baja intensidad (Rosero, 2008) y en la afectación espacial, con una fuerte influencia en zonas específicas de la geografía nacional. No obstante, la expansión del cultivo de coca y el escenario de un proceso de paz con las FARC y el ELN, han definido las lógicas territoriales y relaciones de poder recientes de los actores, de ahí que, a partir de la década del 2000, hay un desplazamiento en la afectación espacial hacia las zonas fronterizas, particularmente, hacia las repúblicas de Venezuela y Ecuador; y un crecimiento exponencial de los cultivos de coca en los departamentos de Nariño y Putumayo. De esta forma, Colombia pasó a convertirse en el principal productor de hoja de coca de la región, sustituyendo a los dos más grandes productores de coca del mundo Bolivia y Perú (Sanchez, 2004).

En términos generales, el conflicto armado ha tenido efectos desfavorables para el desarrollo de Colombia; esto es, sobre la acumulación de capital físico por los ataques a la infraestructura, de capital humano por la violencia homicida, fuga de capital humano y menor cobertura escolar, y además, efectos colaterales como la destrucción de la cohesión social, el aumento en los costos de la canasta básica, deterioro institucional, corrupción y congestión judicial.
La actividad armada también ha tenido secuelas negativas en el sistema general de seguridad social y en salud, impidiendo que se lograra una mayor cobertura del régimen subsidiado. Asimismo, la actividad armada ilegal también impactó en la mortalidad infantil. Y, en el campo político los procesos democráticos se han visto afectados negativamente por una reducción del porcentaje de la masa electoral, especialmente en los municipios que exhibieron actividad armada de las FARC y del ELN, en el caso de los Paramilitares y las Autodefensas los resultados no fueron significativos. En conclusión, los efectos visibles del accionar de los grupos ilegales armados han tenido implicaciones aún peores para el desarrollo de largo plazo de los colombianos (Díaz, 2005).

Sin duda, la continuidad del conflicto colombiano se produce por la persistencia de factores internos y externos, económicos y político-ideológicos que han contribuido a su génesis. Es decir, en los internos se destacan la inamovilidad de la estructura de la propiedad agraria y de la participación política. Y, en cuanto a los factores externos ha sido preponderante la aceptación por parte de la dirigencia colombiana de las directrices de la política norteamericana en términos económicos, políticos y militares, los cuales han dado continuidad a las condiciones básicas del régimen de dominación establecido en Colombia con anterioridad a la segunda guerra mundial (Fajardo, 2014). No obstante, la mutación permanente del Plan Colombia resulta un fenómeno interesante y complejo a la vez que revela varias cosas: como una estrategia de ensayo y error en la que Colombia constituye un caso particular de debilidad estatal que combina formas de institucionalidad estables con disfuncionalidades significativas (Rojas, 2007).

Más allá, el Plan Colombia precisa de un análisis particularizado que, en cierto sentido ha sido considerado como un laboratorio para la implementación de una política de intervención en el caso de estados débiles, pero no colapsados que, se fue configurando de manera tentativa y al ritmo del choque de los intereses y de las visiones de los distintos actores involucrados. Sin embargo, la justificación de este plan está orientada hacia una estrategia antinarcóticos, en lugar de un plan para hacer frente al conflicto armado, con muchas controversias en cuanto a los objetivos y resultados esperados. En resumen, es que no ha tenido el éxito deseado, ni siquiera con su tarea fundamental que fue la lucha al narcotráfico; convirtiéndose en una 
estrategia de carácter incomprensivo, para enfrentar el conflicto colombiano (Latorre, 2015).

El conflicto colombiano, ha incidido negativamente en el Ecuador, para ello es necesario particularizar algunos aspectos de mayor incidencia. Esto es, hasta 1998 la prioridad en cuanto a seguridad y defensa del Estado Ecuatoriano estaba orientada casi en su totalidad hacía la frontera sur, empleando una gran cantidad de recursos en mejorar y mantener la capacidad operativa de sus Fuerzas Armadas, bajo una planificación por amenazas y escenarios. Manteniendo una fuerza admisible en la frontera colombo-ecuatoriana con la tarea de controlar y vigilar la frontera. En conclusión, el Estado Ecuatoriano no tuvo políticas claras ante la problemática del conflicto colombiano; producto de ello, en nuestro territorio, los GIAC ${ }^{1}$, el para-militarismo y las autodefensas hasta el 2008, establecieron sus áreas de descanso, entrenamiento y abasteciendo para el sostenimiento de sus operaciones (García P. R., 2008).

La extensa línea fronteriza, de más de 700 kilómetros, con cientos de pasos fronterizos visibles y no visibles que nacen a orillas del mar y se extiende hasta la Amazonía, es un área estratégica para los GIAC, así como también para el narcotráfico y las redes de la delincuencia organizada y la transnacional y sus delitos conexos (Torres, 2016). Así pues, se constituye en el centro para todos los actos y delitos que están al margen de la ley; así, no es nada raro que en estos sectores de nuestro país, la moneda oficial sea el peso colombiano y que todas las transacciones se las realice con esta moneda. De ahí que, se ha creado una especie de enclave. Sobre la base de las ideas expuestas y desde una visión geoestratégica, en este tipo de conflictos la amenaza tiene la particularidad de buscar o desarrollar un escenario adecuado para potenciar su capacidad operativa y sobretodo garantizar la supervivencia. En conclusión, la presencia como Estado Ecuatoriano en la frontera norte es casi nula, profundizando aún mas en la sociedad ecuatoriana esta problemática que, se ha convertido en una forma de vida por más de 50 años. Por ende, son necesarias políticas claras e integrales, y no solamente que sean orientadas al campo de la seguridad y defensa.

Ahora bien, desde la óptica de la internacionalización del conflicto colombiano, el 01 de marzo del 2008, se constituye en el punto de inflexión. Sin duda, las políticas y sobretodo la falta de una estrategia sólida ante el problema, fue una de las grandes debilidades, convirtiéndonos en reactivos cuando el nivel de conflictividad pasó a una crisis de seguridad y defensa.

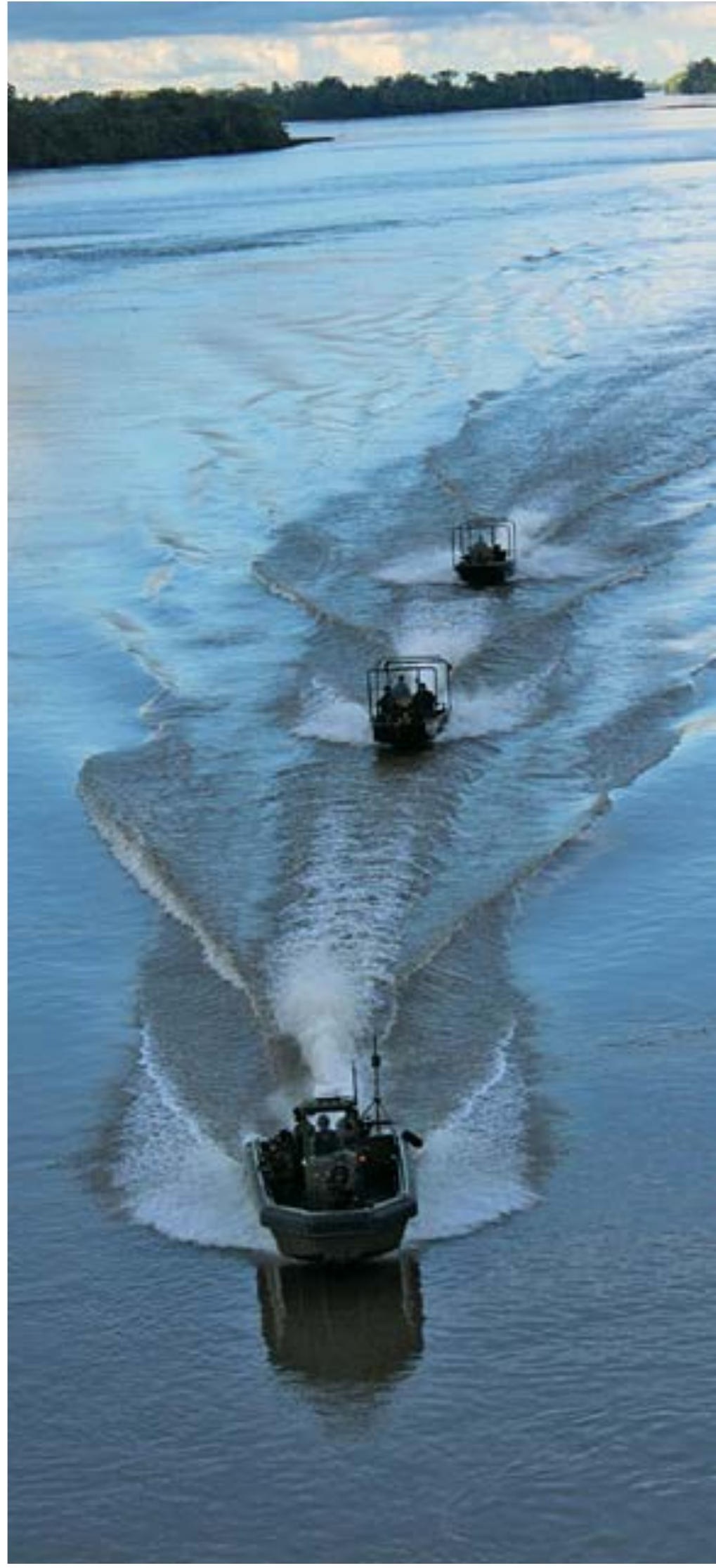

Personal militar realizando patrullajes fluviales en los ríos fronterizos con Colombia.

Fuente: Archivo fotográfico OPSIC - Ejército Ecuatoriano.

1 Grupos Ilegales Armados de Colombia 
Asimismo, esta realidad geopolítica que se configuró como una provocación para los países vecinos por parte de Colombia, ocasionó que se dispare el gatillo del dilema de la seguridad cooperativa, no únicamente para el Ecuador, sino para toda la región de Latinoamérica, que provocó la reacción inmediata del resto de Estados, más aún frente al hecho de una agresión unilateral armada en Angostura, por parte de Colombia (Larenas, 2019).

Dentro de este orden de ideas, qué políticas deben ser las correctas para enfrentar el conflicto de los colombianos, considerando que, en este momento no solo están presentes las relaciones de poder y los factores que componen a un conflicto convencional, sino que se han fortalecido las amenazas directamente relacionadas con el conflicto y que desde mi punto de vista y de varios autores ha mutado con mayor fuerza e incidencia, con un alcance multidimensional; de ahí que, estos recursos son claramente visibles y se relacionan directamente con el campo militar, económico, social, psicosocial, ciberseguridad, guerra de la información, inteligencia, guerra electrónica, la delincuencia transnacional, actos criminales y sobre todo el narcotráfico (Hoffman, 2015). En resumen, y como ejemplo claro de la mutación de esta amenaza, y luego de la firma de la paz con Perú, para fuerzas armadas se volvió prioridad la frontera norte, volcando el esfuerzo principal, y mejorando sus capacidades operativas para enfrentarla.

Desde la perspectiva más general, la estrategia de seguridad y defensa, debe estar enfocada a una seguridad integral, donde el Estado, tiene el papel protagónico, para poder conjugar de forma adecuada todos sus instrumentos, ante la presencia de riegos y amenazas transnacionales. Ahora bien, y teniendo claro que la solución a los conflictos no es exclusividad de los militares, necesitamos considerar que: el componente militar debe alcanzar las capacidades militares de forma equilibrada y adecuada que permitan el cumplimiento de las misiones asignadas; al mismo tiempo, hay que considerar la exigencia del mantenimiento por parte de las Fuerzas Armadas del esfuerzo de adaptación a las nuevas realidades y retos mediante un proceso de transformación continua. (Guindo, 2015). En conclusión, esto conlleva a desarrollar una estructura orgánica y operativa perfectamente adaptable, flexible, interdisciplinaria e interrelacionada con los campos: estratégico, operacional y táctico; y sobre todo al empleo conjunto de las fuerzas en la conducción de las operaciones.

Dentro de este marco, las amenazas híbridas no pueden neutralizarse con una planificación convencional ya que no encajan perfectamente en los modelos tradicionales; para ello, es necesario analizar las formas de combate para determinar el escenario hacia dónde potencialmente podrían evolucionar (Locatelli, 2017).

Por consiguiente, la dinámica cambiante $\mathrm{y}$ mutación constante de las amenazas, precisan de un cambio decidido de la doctrina de empleo de las fuerzas militares. Por lo tanto, la celeridad y amplitud de los avances tecnológicos deben seguir

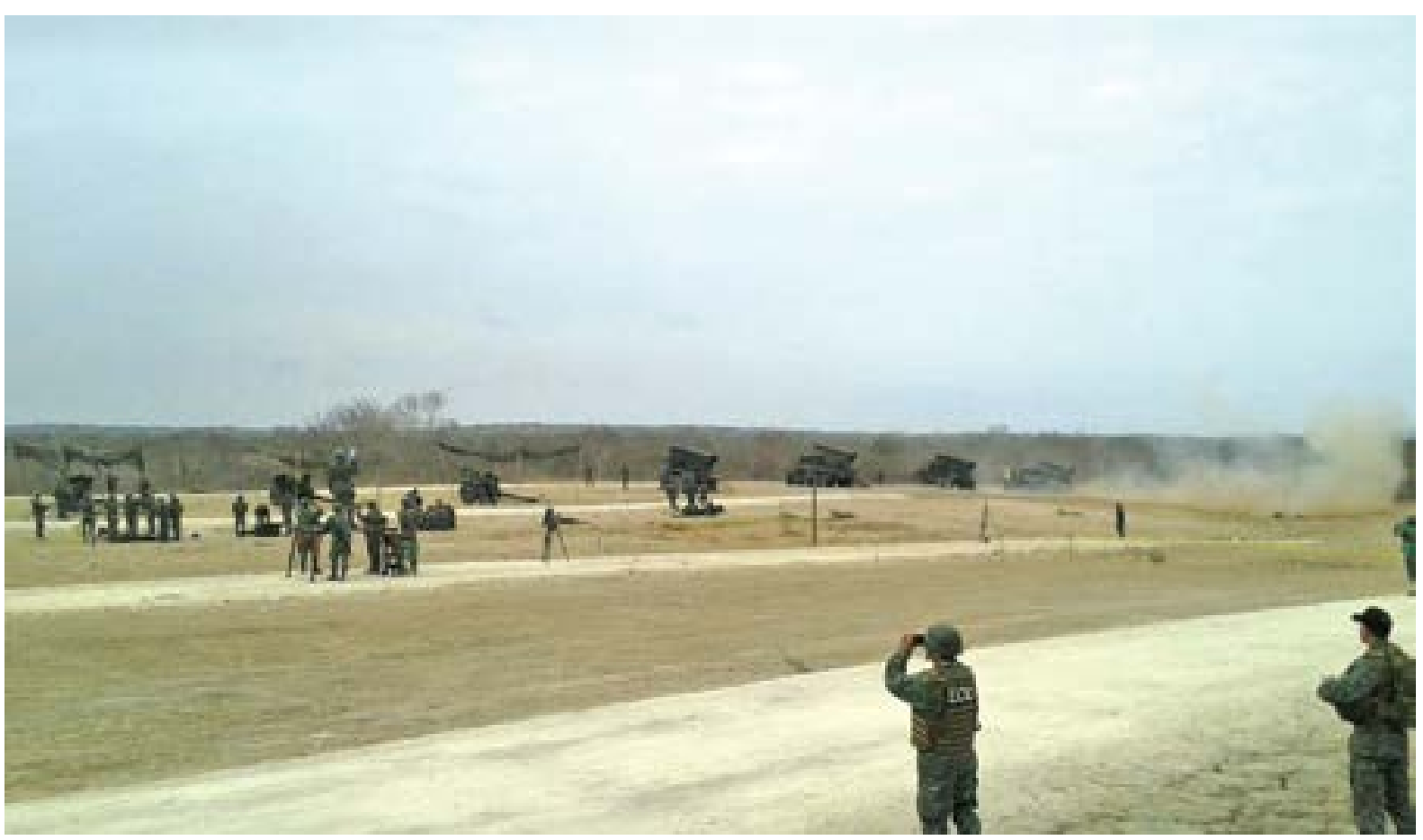

Entrenamiento de unidades militares con sus sistemas de armas en Engabao. Fuente: Archivo fotográfico AGE. 
paralelamente, a fin de crear nuevas tecnologías de la información aplicadas al mando y control. Para ello, se debe fundamentar este desarrollo tecnológico en 3 pilares básicos que son: Un sistema de sensores, comunicación y armamento. En conclusión, esto permitirá el empleo militar de forma descentralizada y autónoma, la digitalización de la realidad, combate de precisión con altos estándares de entrenamiento, control y dominio de la información, aplicación del grado justo de la fuerza para alcanzar los objetivos deseados, una cadena de mando robusta y unificada, y sobre todo el respeto irrestricto a las normas de los Derechos Humanos (García E. , 2016).

Visto de esta forma, los conflictos híbridos deben ser enfrentados de forma integral, con una vinculación gubernamental y no gubernamental, creando un liderazgo integrado entre todas las organizaciones y sector privado, es decir, una acción unificada del Estado, donde deberá predominar la sincronización, integración, coordinación y armonización de las tareas, para afrontar la amenaza (Barreto, 2016). Sin embargo, las Fuerzas Armadas deben lograr las capacidades para contribuir a las acciones integrales, empezando por alcanzar una organización totalmente flexible y dinámica, un equipamiento y alistamiento adecuado, doctrina aplicable a la realidad que se vive y sobre todo una legislación que respalde el accionar de las fuerzas de seguridad y defensa.
Dentro de este marco, cómo lograr esta capacidad en nuestras Fuerzas Armadas, sin que ello constituya una receta, creo, que deberíamos empezar a trabajar sobre la nueva política de la defensa nacional, donde están definidas claramente las amenazas, como son: el conflicto internacional, el terrorismo, grupos ilegales armados, la piratería, la delincuencia y crimen organizado transnacional, el narcotráfico y sus delitos conexos, las catástrofes naturales, alteración del ambiente, pandemias, la pesca ilegal no declarada y no reglamentada y los ciberataques (Libro Blanco, 2018). En síntesis, define claramente hacia donde tenemos que proyectarnos y evolucionar.

Para ello, el Estado Ecuatoriano deberá mantener una actitud defensiva y disuasiva basada en la prevención y alerta temprana que contempla el empleo de la fuerza militar para gestionar riegos y contrarrestar amenazas estatales y no estatales, sustentando en el concepto de legítima defensa (Jarrín, 2018). Orientando su máximo esfuerzo a: ejercer el control efectivo del territorio nacional, apoyar a las instituciones en la protección de la población; fortalecer las capacidades estratégicas de las Fuerzas Armadas; contribuir a la cooperación internacional; y contribuir al desarrollo nacional, a través de cooperación intersectorial, investigación e innovación en las industrias de la defensa (Libro Blanco, 2018). Por lo tanto, está claramente definido el accionar de Fuerzas Armadas.

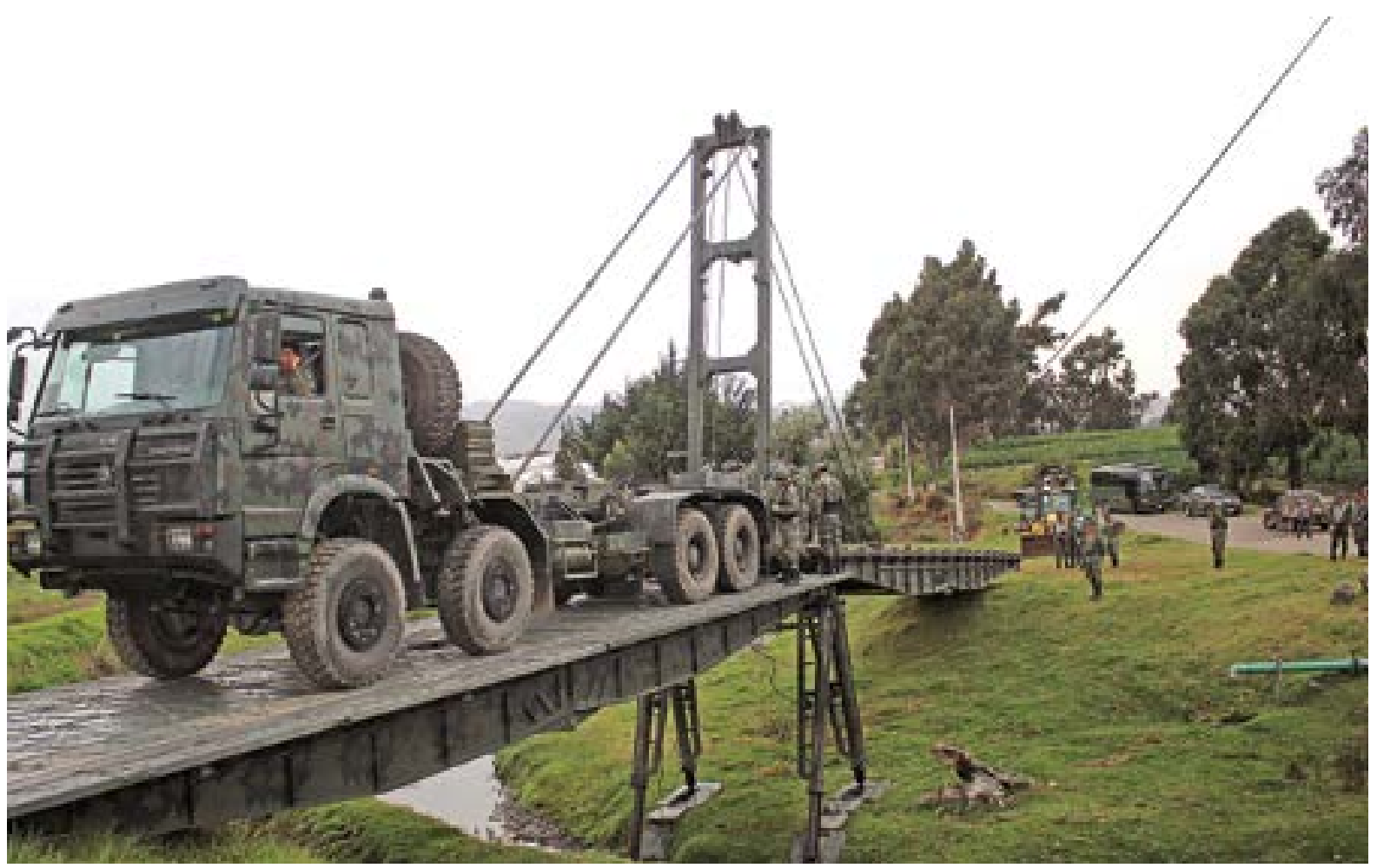

Tendido de puentes del Cuerpo de Ingenieros del Ejército. Fuente: Archivo fotográfico OPSIC - Ejército Ecuatoriano. 
Evidentemente, ante la no existencia de conflictos armados interestatales en los últimos años en América Latina, por la adopción de la diplomacia como la vía para su solución, ha sido considerada como una zona de paz; empero, no se puede ni debe descarta el empleo del Poder Militar debido a la confrontación de intereses y a un desbalance muy significativo del actual poder relativo de combate que existente entre Fuerzas Armadas de la región. Por ello, y bajo una óptica multidimensional y mundialización de los conflictos las Fuerzas Armadas ecuatorianas debemos estar preparados para enfrentar, estos nuevos retos en el campo de la seguridad y defensa (Libro Blanco, 2018).

Por otra parte, no solo en teoría las metodologías operacionales conjuntas han demostrado su eficacia en el combate, considerando que en la actualidad el ambiente operacional está claramente identificado y comprende los dominios terrestre, marítimo, aéreo, cibernético y espacial (Tormey, 2017). Sin embargo, el primer paso es comprender claramente cuáles son los potenciales ambientes operacionales que se deben abordar. En este ámbito, se habla del concepto de operaciones multidominio aún en desarrollo, que son definidas según el General David G. Perkins como: "un descendiente del Combate Aeroterrestre, en donde cada paso de su proceso evolutivo está concebido para enfrentar los desafíos prevalecientes con el desarrollo de nuevas y diferentes soluciones" (Perkins, 2018). Consecuentemente, las operaciones del presente y del futuro deben ser planificadas y conducidas con mucha imaginación, de tal forma que se pueda fundir el arte con el diseño de una operación.

Cabe considerar por otra parque que, la planificación por capacidades es un sistema de planeamiento que pretende dotar a las Fuerzas Armadas de las capacidades militares más adecuadas para satisfacer una amplia gama de retos presentes y futuros en un marco de incertidumbre estratégica, y recursos económicos limitados; con coherencia, transparencia y flexibilidad, y sobre todo de idoneidad para transformar los objetivos de la defensa nacional en planes de acción. Ahora bien, hay quienes sostienen que no sabemos para qué las queremos y que se utiliza para justificar la adquisición de los grandes sistemas de armamento y material, poniendo especial atención sobre el elemento tecnológico de las Fuerzas Armadas. No obstante, se podría estar ignorando la cultura estratégica de los potenciales adversarios; debido, a que el escenario actual con la potencialidad que alcanzó Rusia y China en cuanto a su poder militar podría motivar a los Estados que se vean amenazados retornen al planeamiento militar basado en amenazas y escenarios (Colom, 2017).

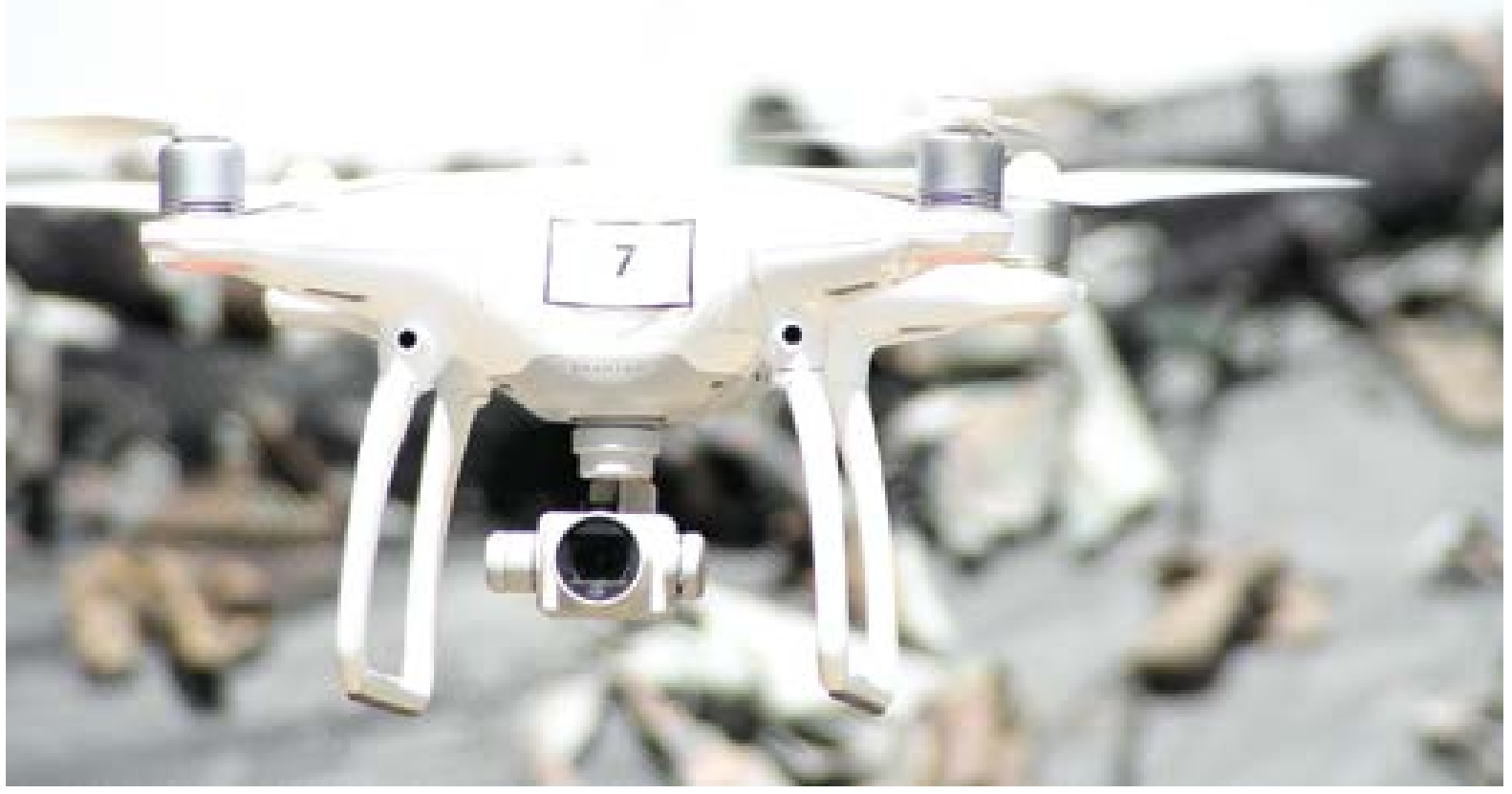

El uso de tecnología actualizada es una de las competencias necesarias para mantener la soberanía e integridad territorial.

Fuente: Archivo fotográfico OPSIC - Ejército Ecuatoriano. 
Finalmente, el marco analizado y conceptualizado nos proporciona herramientas muy valiosas para definir claramente hacia donde debemos evolucionar. Si bien, hemos alcanzado una cierta capacidad operativa para enfrentar las amenazas del conflicto colombiano, sin embargo, no ha sido suficiente. Ahora bien, planificar sobre capacidades podría ser la mejor solución, sin embargo, este sistema de planeamiento requiere de un ingente de recursos económicos, que cada vez son más escasos. A pesar de ello, no podemos estancarnos, esto, conlleva a un debilitamiento y posiblemente a una desprofesionalización de la institución armada, a consecuencia de una falta de toma de decisiones, para delimitar el campo de acción de Fuerzas Armadas en su ámbito de acción, dentro de un ambiente operacional cada vez más perplejo y complejo.

\section{Conclusiones}

Sin lugar a cuestionamientos, el conflicto armado de Colombia desde su inicio y hasta la presente fecha ha sufrido una constante mutación, que ha incidido y lo seguirá haciendo de forma directa en el Ecuador, afectando en los campos de seguridad, defensa, psicosocial y crecimiento económico, con un incremento de la inseguridad y la tranquilidad de los ciudadanos. La tarea para el Estado Ecuatoriano bajo el enfoque de una seguridad integral no es fácil, ni tampoco se debe minimizar el problema. Para ello, es necesario visualizarlo desde una perspectiva multidimensional, con soluciones integrales, con muchísima imaginación ante la escasez de recursos. Ya que, la incertidumbre y el grado de complejidad para solucionar estos problemas es cada vez mayor.

La Nación como tal, siempre exigirá de sus Fuerzas Armadas las competencias necesarias para mantener la soberanía e integridad territorial y apoyar a la seguridad integral del Estado. No obstante, el ambiente operacional cambiante, en donde la amenaza u enemigo desafiará nuestra capacidad de maniobrar, incluso desde fuera del área de operaciones con respuestas innovadoras y eficaces en los dominios, terrestre, marítimo, aéreo, cibernético, espectro electromagnético y quizá con menor incidencia en el espacial, hará más difícil el empleo eficiente. Consiguientemente, resulta indispensable desarrollar las siguientes capacidades:

a. Contar con una organización flexible y dinámica que se adapte a los diferentes dominios, con una respuesta rápida y contundente.

b. Equipamiento adecuado de acuerdo a las necesidades en cada uno de los dominios, para ello se debe priorizar el desarrollo de tecnologías propias, a través del impulso de los ingenios militares.

c. Entrenamiento y capacitación permanente en escenarios reales. Que nos permitan alcanzar altos estándares de educación, para una preparación eficiente.

d. Alcanzar el empleo conjunto, para potencializar cada componente en su dominio, con un mando unificado, y una planificación a través del arte y diseño operacional.

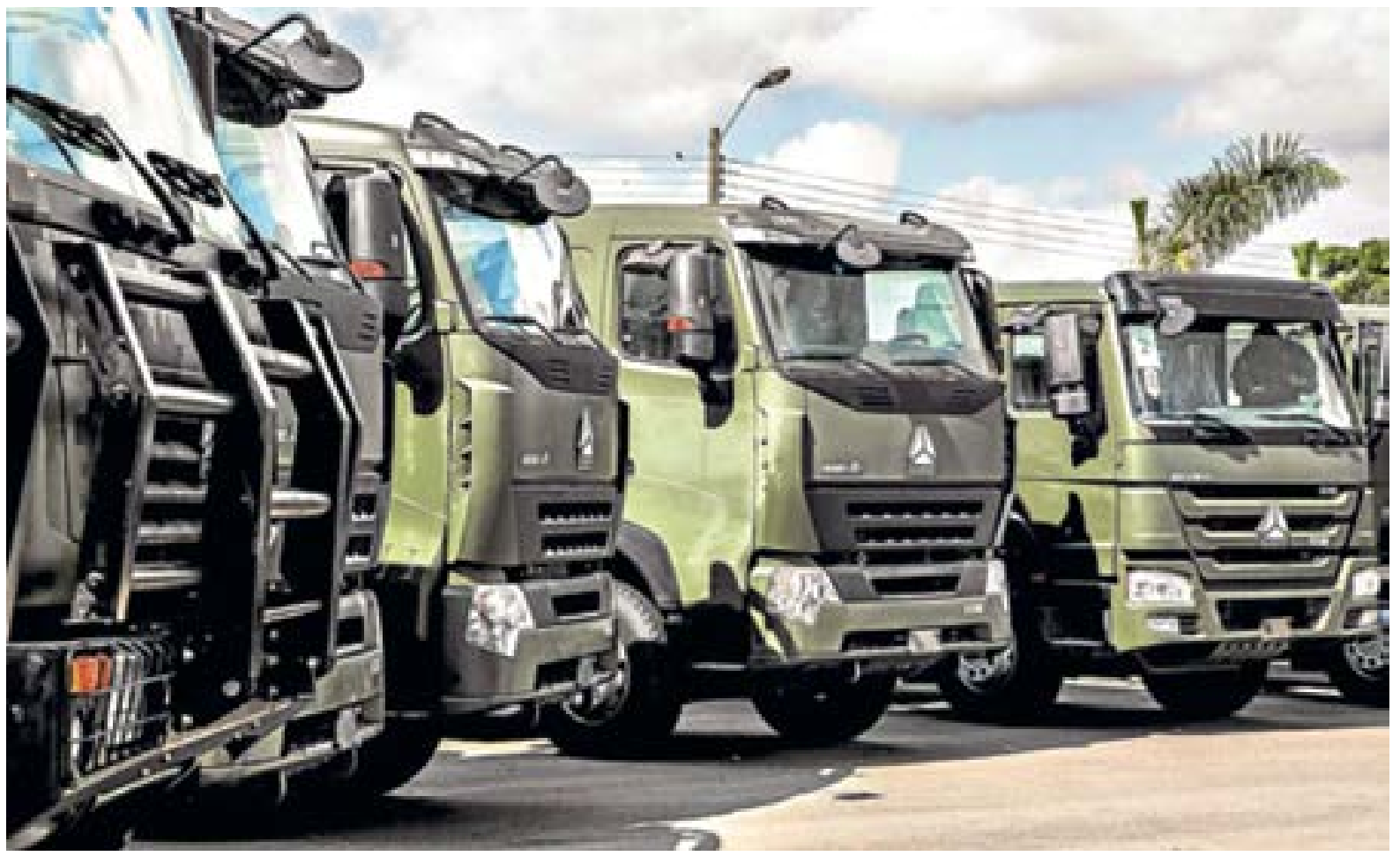

Incorporación de vehículos chinos para fortalecer las capacidades logísticas del Ejército Ecuatoriano en el año 2015. Fuente: Archivo fotográfico OPSIC - Ejército Ecuatoriano. 
e. Un sistema de mando y control robusto, con sistemas de telecomunicaciones más compactos, flexibles, con capacidad de integración e información en tiempo real. Para lograr la superioridad en la información y en la decisión.

f. La capacidad de ejecutar operaciones de ciberdefensa y ciberseguridad.

g. La capacidad de ejecutar operaciones de guerra electrónica.

h. Sistemas no tripulados en cualquiera de sus modalidades (terrestres, acuáticas o áreas)

i. La capacidad de inteligencia artificial y biometría.

j. Crear nuestra propia doctrina, aplicada a nuestra realidad, con un organismo propio de generación de doctrina a través de la planificación, investigación y desarrollo, experimentación y evaluación y edición y difusión, para enfrentar las amenazas con menor dosis de incertidumbre y complejidad.

k. Movilidad y proyección mediante la adquisición de medios que garanticen la proyección estratégica y la movilidad táctica de la fuerza para aplicar el poder militar donde y cuando sea necesario.

1. Apoyo logístico integral y conjunto, apoyándonos en otros organismos civiles y/o militares para así garantizar el sostenimiento de la fuerza desplegada en la zona de operaciones.

$\mathrm{m}$. Un sistema de inteligencia que integre el nivel estratégico, operacional y táctico, para minimizar los riesgos ante la presencia de cualquier amenaza, con un nivel muy bajo de incertidumbre.

Para alcanzar estas capacidades es primordial la acción decidida del Estado Ecuatoriano, a través de una visualización permanente de las afectaciones y los potenciales riesgos a la seguridad y defensa como una política permanente, y sobre todo con acciones concretas en las relaciones internacionales a través de la materialización de alianzas y coaliciones; concretando la entrega de los recursos necesarios; para ello, es ineludible la motivación por parte del ente militar, para impulsar las iniciativas que contribuyan a preservar la seguridad y bienestar de los ciudadanos u otras necesidades públicas. Sin embargo, no debemos perder de vista que, la institución armada cuenta con un talento humano que debe potencializar la falta de recursos económicos, a través del entrenamiento $\mathrm{y}$ capacitación permanente, para desarrollar el arte de la guerra. Nadie nos puede o debe quitar las fuerzas y el talento de crear y pensar; ya que con muchísima imaginación e iniciativa se logrará desarrollar las capacidades necesarias para enfrentar los riegos y amenazas presentes y futuras, que cada vez tienen una gran medida de incertidumbre y de complejidad; en una línea de tiempo adecuada y alcanzable.
[1] Barreto, C. (2016). LA GUERRA HIBRIDA EN EL SIGLO XXI. RECOMENDACIONES PARA ENFRENTAR LA AMENAZA. Los ejércitos y el sistema internacional contemporáneo: Nuevas amenazas, tendencias y desafíos, 114.

[2] Colom, G. (2017). Una revisión del planeamiento de la defensa por capacidades en España (2005-16). Papeles de Europa, 38-40.

[3] Díaz, F. S. (2005). LOS EFECTOS DEL CONFLICTO ARMADO EN EL DESARROLLO SOCIAL COLOMBIANO, 1990-2002. ISSN 1657-7191, 1-64.

[4] Fajardo, D. (2014). Estudio sobre los orígenes del conflicto social armado, razones de su persistencia y sus efectos más profundos en la sociedad colombiana. Comisión Histórica del conflicto y sus víctimas, 1-32.

[5] García, E. (2016). Altas tecnologías, conflictos armados y seguridad humana. Araucaria. Revista Iberoamericana de Filosofía, Política y Humanidades, vol. 18, núm. 36, Universidad de Sevilla, 265-293.

[6] García, P. R. (2008). Las autodefensas y el paramilitarismo en Colombia (1964-2006). CONfines, 1-2.

\section{REFERENCIAS}

[7] Guindo, M. G. (2015). LA GUERRA HIBRIDA: NOCIONES PRELIMINARES. Documento de Trabajo del Instituto Español de Estudios Estratégicos (IEEE), 15.

[8] Hoffman, F. G. (2015). Hybrid vs. Compound War: The Janus Choice of Modern War. Defining Today's Multifaceted.

[9] Jarrín, M. D. (2018). POLÍTICA DE LA DEFENSA NACIONAL DEL ECUADOR EDICIÓN 2018. QUITO: IGM.

[10] Larenas, A. M. (2019). Google académico. Obtenido de http:// repositorio.uasb.edu.ec/ bitstream/10644/3865/1/T1378-MRIMoscoso-Ecuador.pdf

[11] Latorre, J. P. (2015). El Plan Colombia o el desarrollo como seguridad. Revista Colombiana de Sociología, 38(1), 63-82. , 5-10.

[12] Libro Blanco. (2018). Política de la Defensa Nacional Libro Blanco 2018. Quito: IGM 2018.

[13] Locatelli, O. A. (2017). Guerras Híbridas su centro de gravedad y la victoria. Prepararse ¿Para qué guerra?. Año 9 Nro. 17. Argentina: Escuela Superior Conjunta de Argentina: 40-46.
[14] Perkins, G. D. (2018). La batalla multidominio impulsando el cambio para ganar en el futuro. Military Review, 20-30.

[15] Rojas, D. M. (2007). Plan Colombia más de lo mismo. ISSN 0121-5612, 14-37.

[16] Sanchez, A. M. (2004). GEOGRAFÍA DE LOS CULTIVOS ILÍCITOS Y CONFLICTO. ISSN 1657-7191, 1-64.

[17] Tormey, M. T. (2017). Las operaciones de multidominios y el apoyo aéreo cercano Una nueva perspectiva. Military Review, 20-30.

[18] Torres, R. (2016). La caliente frontera norte. Cinco militares retirados exponen las razones por las que Ecuador debe reforzar la vigilancia militar La zona es estratégica para el tráfico de drogas, pág. 1.

[19] Yaffe, L. (2011). Conflicto armado en Colombia: análisis de las causas económicas, sociales e institucionales de la oposición violenta. Revista CS , 191-192. 